\title{
EFEITOS DA BUROCRACIA NA AVALIAÇÃO DA EDUCAÇÃO SUPERIOR
}

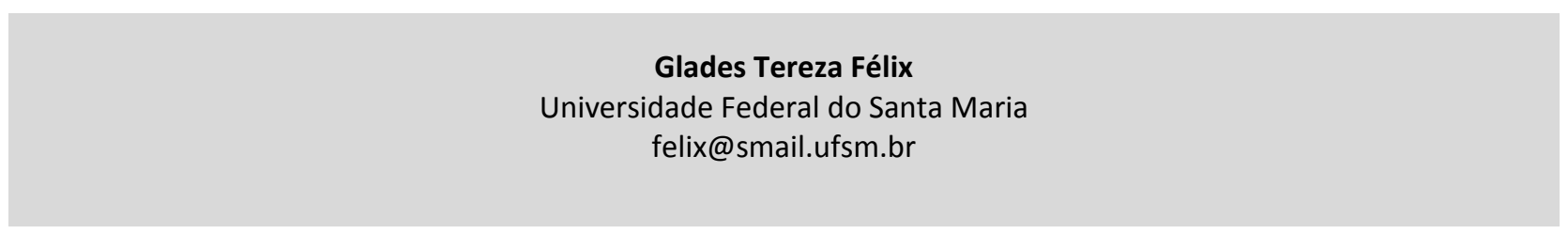

Artigo submetido em outubro/2013 e aceito em dezembro/2013

\section{RESUMO}

Este artigo situa-se na fronteira do debate geral das políticas de educação superior. Tais políticas estão vinculadas às estratégias de inserção da economia nas grandes transformações em âmbito mundial. Nesse contexto, são instaurados processos de avaliação da educação superior que contribuem para a redefinição da relação entre o Estado e o sistema de ensino superior. É nessa perspectiva que se situa o objeto deste estudo identificar o modelo de gestão pública que conduziu a incorporação formal e definitiva da avaliação como ato regulatório e compulsório no primeiro Governo FHC (1995-2002). De caráter descritivo, com uma abordagem qualitativa, na revisão de literatura destacamos as características do Estado Burocrático e do Estado Gerencial. Igualmente, estudamos o conceito e o significado de eficiência no plano administrativo de ambos os Estados. Os resultados mostraram que o modelo de gestão pública estava em transição, quando a política pública denominada avaliação da educação superior tornou-se regulatória, definitiva e compulsória no país, pois mesmo tendo a base no modelo Gerencial, tal concretização só foi possível por meio de ações burocráticas ancoradas no excesso de legislações. Conclui-se que a emergência da avaliação da educação superior na década de 90 ampliou a burocracia.

PALAVRAS-CHAVE: Avaliação, educação superior, burocracia, eficiência, regulação.

\section{EFFECTS OF BUREAUCRACY IN ASSESSMENT OF HIGHER EDUCATION}

\begin{abstract}
This article is located on the border of the general debate of higher education policies. Such policies are linked to the strategies of integration of the economy in major changes worldwide. In this context, are established procedures for assessing higher education that contribute to the redefinition of the relationship between the state and higher education system. It is in this perspective that situates the subject of this study to identify the model of public management that led to formal incorporation and final assessment as regulatory act and compulsory in the first Cardoso administration (1995-2002). Descriptive in nature, with a qualitative approach in the literature review highlight the
\end{abstract}

characteristics of the Bureaucratic State and State Management. Also, we study the concept and meaning of efficiency in the administrative plan of both states. The results showed that the model of public management was in transition, when the policy called evaluation of higher education has become regulatory, permanent and compulsory in the country as having the same Model Management based on such achievement was only possible through bureaucratic actions anchored in excess legislation. We conclude that the emergence of higher education evaluation in the 90 expanded the bureaucracy.

KEYWORDS: Evaluation, higher education, bureaucracy, efficiency, regulation. 


\section{EFEITOS DA BUROCRACIA NA AVALIAÇÃO DA EDUCAÇÃO SUPERIOR}

\section{INTRODUÇÃO}

O propósito deste artigo é apresentar uma discussão recorrente no âmbito das políticas públicas; a relação e a tensão entre burocracia, eficiência e processo de avaliação da educação superior durante os Governos Fernando Henrique Cardoso (1995-2002). Não se pretende esgotar a questão, mas, tão somente, discutir pontos implicativos, tendo como objetivo delinear o modelo de gestão pública que levou à incorporação formal e definitiva da avaliação como ato regulatório e compulsório a partir daquela gestão.

No primeiro segmento, apresentaremos o surgimento e as diferenças entre Estado Burocrático e Estado Gerencial no Brasil. No segundo, levantaremos o significado e os resultados da apropriação do termo "eficiência" nos planos administrativos do Estado burocrático e gerencial. Após, situaremos a implementação do processo de avaliação da educação superior nos Governos FHC. Para finalizar, faremos o contraponto da tensão entre eficiência e burocracia e os modos pelos quais pode-se instigar processos de avaliação mais lineares e menos abertos, mais rígidos e menos flexíveis, mais quantitativos e menos qualitativos, capazes de reproduzir uma prática padronizada, a fim de enfrentar a complexidade do que é avaliar em nosso tempo.

\section{ESTADO BUROCRÁTICO E ESTADO GERENCIAL NO BRASIL}

Na obra Os donos do Poder, Faoro (1957, p.75) descreve que o Estado brasileiro de 1900 era um Estado Oligárquico e patrimonialista, no qual uma elite de poucos senhores de terra, enquanto políticos dominava o país, pois reproduzia o sistema das monarquias absolutas, em que o patrimônio público e o privado se confundiam, sendo o Estado uma propriedade do Rei. Empreguismo e nepotismo eram a regra. Com a ascensão do capitalismo industrial e das democracias parlamentares no século XIX, tais práticas começam a se tornar incompatíveis frente ao capitalismo defensor da separação entre o público e o privado. Considerando-se tal insustentabilidade, surge a administração burocrática.

\footnotetext{
Com uma conotação negativa, tendo sido empregado inicialmente por Gournay, um economista fisiocrata no século XVIII; expressava o corpo de funcionários e empregados do Estado absolutista francês, incumbido de funções específicas sob a dependência do Rei. A expressão se difundiu e também foi utilizada para denegrir o formalismo e o corporativismo da administração pública, especialmente na Alemanha. (GIRGLIOLI, 1995, p. 124).
}

Foi no século $\mathrm{XIX}$, com base nos princípios da administração do exército da Prússia, organizado de maneira hierarquizada e monocrática, que Weber tomou como objeto de estudo a burocracia, baseando-se no princípio do mérito profissional. Por essa perspectiva, o autor admitia ser a burocracia uma forma superior de organização social e de dominação, capaz de levar as organizações a atingirem altos graus de eficiência.

O modelo analítico weberiano, sistematizado a partir da sociologia política e não na teoria das organizações, baseia-se no formato de um sistema de critérios de eficiência conhecidos pelas seguintes características:

1. Estrutura de autoridade pessoal; 
2. Hierarquia de cargos, baseada em um sistema de carreiras altamente especificadas;

3. Cargos com claras esferas de competência e atribuições;

4. Sistema de livre seleção para preenchimento dos cargos, baseados em regras

1. específicas e contrato claro;

5. Seleção com base em qualificação técnica (nomeação e não eleição);

6. Remuneração expressa em moeda e baseada em quantias fixas graduadas conforme o nível hierárquico e a responsabilidade do cargo;

7. O cargo como a única ocupação do burocrata;

8. Promoção baseada em sistema de mérito;

9. Separação entre os meios de administração e a propriedade privada do burocrata;

10. Sistemática e rigorosa disciplina e controle do cargo.

Observa-se que esses critérios característicos da tradição weberiana enfatizam estruturas, regras, procedimentos e papéis; portanto, apenas tornam as burocracias capazes de alto grau de eficiência. $O$ trabalho de Weber deu origem à tradição de se pensar a burocracia, a qual foi marcante no período do Estado Keynesiano. Por outro lado, foi bastante criticado por várias escolas de pensamento pelo reconhecimento de inúmeras disfunções. Acrescente-se à série de críticas as de Lane (1993), desvalorizando o trabalho do autor quando aponta que as burocracias não são impessoais; nelas há uma teia de relações humanas.

A adesão dos funcionários às regras e normas chega facilmente ao ritualismo e, consequentemente, a ineficiência; a capacidade de iniciativa dos subordinados fica seriamente limitada pela centralização e determinação unilateral de conduta administrativa por parte dos superiores; o modelo é muito mecanicista para ser eficiente em situações que exigem uma elevada capacidade de flexibilidade e de adaptação (GIRGLIOLI 1995, p. 129).

Em termos de Brasil, a natureza da sociedade capitalista e do Estado burocrático começa a se formar a partir da década de 1930, na era Vargas, quando dispensa um poder político indiscutível para o lado estatal, no qual a nova burocracia passou a ter uma função econômica importante. Tais aspectos vão percorrer as décadas seguintes, trazendo consigo grandes mudanças políticas, econômicas, sociais, culturais e infraestruturais. Para Pires e Piccinini (1999), era essencial o monopólio estatal no setor de infraestrutura, em razão da importância desta para o desenvolvimento das outras atividades econômicas e para a integração social.

Isso estruturou uma prática burocrática de carreira na administração pública direta, pois o Conselho Federal do Serviço Público Civil (1936) foi o embrião do Departamento Administrativo do Serviço Público (DASP), segundo Gouvêa (1999, p. 99), o guardião dos princípios centralizadores e hierárquicos da burocracia clássica.

A partir disso, o Estado tornou-se o principal motor de desenvolvimento econômico, pois passou a controlar os investimentos e a definir as empresas e os setores produtivos que comandavam a economia. Na visão de Draibe (1985, p. 21), a burocracia passou a ter, na defesa da intervenção do Estado, um unificador, um forte executivo, um aparelho administrativo moderno e complexo, operando através de um corpo cada vez maior e mais sofisticado de funcionários. Martins (1985, p. 34) complementa que o Estado cria e reproduz uma burocracia dotada de interesses próprios, que se realizam através do intervencionismo estatal.

Foi durante o Estado Novo do Governo Getúlio Vargas, pelo viés autoritário, que tardiamente implantou-se a reforma burocrática no Brasil, enquanto países como Inglaterra, 
França, Alemanha e Estados Unidos promoviam o surgimento de uma burocracia moderna, voltada para a produção, por meio da Civil Service reform.

A reforma de 1936 fora imposta de cima para baixo. Não correspondia as reais necessidades contraditórias da sociedade e da política brasileira. O Estado necessitava de uma burocracia profissional, mas fazia concessões ao velho patrimonialismo que na democracia nascente assumia a forma de clientelismo. Por outro lado, a elite burocrática que assumiria o papel de liderança política na transição para o capitalismo industrial deveria ser profissional, mas liberada das amarras do formalismo burocrático. (PEREIRA, 2001, p.12).

Com a deposição de Vargas, em 1945, a reforma ficou sem o respaldo do regime autoritário, e elementos patrimonialistas e clientelistas ressurgem com força. O DASP perde parte de suas atribuições, sendo a reforma conduzida por ações rotineiras e sem relevância pelo Governo que assumiu. Ao voltar ao poder, entre 1951 e 1954, Vargas retoma esforços, tentando completar a implementação da Administração Pública Burocrática no país; entretanto, as forças comprometidas com o desenvolvimento econômico, somadas ao atraso do patrimonialismo e clientelismo, conspiravam contra tal intento. Reflexo dessa situação vai perpassar aos governos de JK (1956/1960) e do regime militar (1964/1984), porque aquele se mostrava incompatível com as necessidades do país, cujo Estado assumia, cada vez mais, demandas atinentes à cidadania, como saúde, educação, cultura, previdência, assistência social, pesquisa científica, além da área econômica, em torno do sistema financeiro, da estabilidade da moeda, das relações internacionais, dos serviços públicos e de infraestrutura.

No momento em que o pequeno Estado liberal do século XIX deu definitivamente lugar ao grande Estado social e econômico do século XX, verificou-se que não garantia nem rapidez, nem boa qualidade, nem custo baixo para os serviços prestados ao público. Na verdade, a administração burocrática é lenta, cara, auto-referida, pouco ou nada orientada para o atendimento das demandas dos cidadãos. (PEREIRA, 1996, p. 5).

Contudo, o cenário, a partir de 1964, aponta que as elites principais eram do setor agrário. Com o golpe militar, elas foram promovidas a elites estatais, o que elevou a capacidade de manipulação dos recursos públicos. Certamente, a concentração do poder executivo federal nas mãos das elites técnicas transformou os recursos do Estado em recursos políticos. Foi assim que a tecnocracia e as elites dividiram o Estado e a distribuição dos recursos públicos.

Isso é explicado com precisão pelo conceito da formação de anéis burocráticos ${ }^{1}$, cunhado por Cardoso (1993, p.151), relativos a grupos privados que interagem com órgãos públicos. Foi assim que:

o enorme edifício burocrático construído basicamente na era Vargas, na época da centralização estatal do Brasil, implantou inúmeras agências do Estado em todo o interior do país. São múltiplas as agências cartoriais, administrativas, de

\footnotetext{
${ }^{1}$ Conceito desenvolvido por FHC, em 1971. Representa situação em que a burocracia desempenha a função de prover favores, isto é, além de criar entre o Estado e interesses privados uma teia de cumplicidade que mobiliza interesses e grupos, principalmente em setores dinâmicos da economia, representa também uma teia mais difusa, orientanda por relações de lealdade pessoais. Torna cúmplice desde o vereador, o deputado, o funcionário público, o industrial, o comerciante, funcionando, assim, a burocracia como parte de um sistema mais amplo sem depender de partidos, sindicais, etc.
} 
fiscalização, como também os serviços da administração de saúde e educação. (AVELAR, 1996, p. 40).

Após as duas guerras mundiais, houve a redefinição dos valores burocráticos, quando o Estado sente-se obrigado a se recuperar, emergindo o Estado Social preocupado com saúde, moradia, educação etc. Outra causa advinda do aumento das atividades do Estado era o pensamento de que a economia e o mercado tinham regras próprias, pois segundo a teoria de Hayek, em 1947 na Suíça, surgia a noção de neoliberalismo como perspectiva acadêmica. Como lógica política e econômica, predominou no cenário global com Thatcher, na Inglaterra (1979), e Reagan, nos EUA (1980). Na América Latina, esse projeto se desenvolve a partir do Chile, com Pinochet. Tais princípios pragmáticos se explicam na assimilação dos setores políticos sobre o aprofundamento da crise estrutural do modelo de acumulação, os quais levam à opção da reestruturação do processo de (re)produção do capital.

Com a queda do muro de Berlim e o Consenso de Washington (1991), esse pensamento toma conta do panorama mundial, oportunizando uma grande reforma na administração pública dos países centrais, rumo a uma administração pública gerencial.

Em relação ao Brasil, estudos de Pereira apontam duas possibilidades. A primeira defende que a "ideia" de administração pública gerencial nasceu com a primeira reforma burocrática de Vargas dos anos 30.

Em 1938 temos um primeiro sinal de administração pública gerencial, com a criação da primeira autarquia. Surgia então a ideia de que os serviços públicos na administração indireta deveriam ser descentralizados e não obedecer a todos os requisitos burocráticos da administração direta ou central. (PEREIRA 1996, p. 6).

A segunda, o autor denominou de "primeira tentativa" de implementação da administração gerencial. Trata-se do Decreto-lei 200/1967, criado em plena ditadura militar, sob a inspiração de Hélio Beltrão que, posteriormente, como Ministro da Desburocratização, vai criticar a centralização do poder, o formalismo e a desconfiança no excesso de regulamentação burocrática, definindo o Programa Nacional de Desburocratização (1969), cuja política visava minimizar a condição de pós-colonial dos usuários à condição de cidadão. Ampliando as ideias de Pereira (1996), foi uma tentativa de superação da rigidez burocrática, mas teve consequências contraditórias porque eivadas de práticas clientelísticas ou fisiológicas.

Após longa e difícil transição, o país retoma, em 1985, o regime democrático em meio à crise fiscal, alheia à necessidade de rever a forma de intervenção do Estado na economia. Para Pereira (1996, p.18), pretendia-se o pensamento Keynesiano, porém dominava o nacionalismodesenvolvimentista, protecionista e estatista.

Se, por um lado, em 1988, o Brasil se descentralizava no plano político, com o advento da Constituição Federal, por outro, centralizava-se no poder administrativo, retroagindo à reforma burocrática de 1936, quando limitou a autonomia das agências e empresas do Estado. Na ideia de Pereira (1996), são muitas contradições.

Em um momento em que o país necessitava urgentemente reformar a sua administração pública, de forma a torná-la eficiente e de melhor qualidade, aproximando-a do mercado privado de trabalho, o inverso é realizado. O serviço público tornou-se ineficiente e mais caro e o mercado de trabalho público separou-se completamente do mercado de trabalho privado. A separação foi 
proporcionada não apenas pelo sistema privilegiado de aposentadorias do setor público, mas também pela exigência de um regime jurídico único, que levou a eliminação dos funcionários celetistas, e pela afirmação constitucional de um sistema de estabilidade rígido, que tornou inviável a cobrança de trabalho dos servidores. (PEREIRA, 1996, p. 14).

Em 1995, diante da crise de um Estado Burocrático-industrial, FHC assume a Presidência da República, propondo uma novidade para o país, ou seja, a Reforma do Estado em geral e, em particular, do aparelho do Estado e de pessoal nos moldes da administração gerencial. O novo está no fato de que tal propositiva não havia sido objeto de discussão da Constituinte e menos ainda da campanha presidencial de 1994, quando, então, surge a oportunidade para a reforma do Estado.

Para Mafra (2010, p. 1), tal administração é construída sobre bases que considera o Estado uma grande empresa, cujos serviços são destinados aos seus clientes, outrora cidadãos, na eficiência dos serviços, na avaliação de desempenho e no controle de resultados. Para Abrúcio (1997), o modelo da Administração Pública Gerencial apresenta as seguintes características.

1. Orientada para clientes e resultados;

2. Flexibilidade;

3. Competitividade administrada;

4. Descentralização;

5. Estado atuante, em contraposição à visão liberal;

6. Orientação para critérios de eficiência (tecnologia gerencial);

7. Estruturas horizontalizadas;

8. Agências regulatórias independentes;

9. Contrato de gestão, etc.

Diferentemente de Vargas, foi com o intuito de reformar e reconstruir o Estado para que este se transformasse em um agente efetivo e eficiente de regulação do mercado e de capacitação das empresas no processo competitivo internacional, que o presidente $\mathrm{FHC}$ providenciou a transformação da Secretaria de Administração Federal (SAF) no Ministério da Administração Federal e Reforma do Estado (MARE).

Segundo o Ex-ministro Bresser Pereira, a formação das novas ideias por ele lideradas se baseou nas reformas de países da Organização para a Cooperação e Desenvolvimento Econômico (OCDE), nos fundamentos da obra Reinventando o Governo, de autoria dos americanos Osborne e Gaebler, e também na disciplina new public management (Reino Unido). Dessa forma, surgiu a formulação da reforma, através da elaboração do Plano Diretor da Reforma do Aparelho do Estado (PDRAE).

Esse Plano estabelece diretrizes a serem implementadas dentro da administração pública brasileira, objetivando o gerencialismo por meio da redução da presença do Estado na Economia. A ênfase deve sair do controle formal para o controle de resultados ou controle a posteriori.

Isso exigiu reformas na Constituição de 1988, as quais foram parte essencial da Reforma Administrativa de 1995, visto que alteraram instituições normativas fundamentais. Outras reformas, porém, foram de caráter infraconstitucional (independe de alteração constitucional); por exemplo, em 1997, criaram-se as agências executivas (atividades exclusivas do Estado) e as Organizações Sociais (híbridas entre Estado e Sociedade). 
Em se tratando de alterações constitucionais, cabe resgatar a responsabilidade da Emenda Constitucional no 19/1998, porque foi a normativa que alterou o modelo de Administração Pública no Brasil e introduziu o novo modelo, baseado no princípio da eficiência; ao mesmo tempo em que alterou o regime administrativo brasileiro, seus princípios e normas, extinguiu, também, o regime jurídico único (RJU).

Portanto, o objetivo da Reforma Administrativa foi transitar de uma Administração Burocrática para Gerencial de caráter profundo, o que obviamente, não se efetivou de um dia para o outro, nem com a mesma intensidade em todos os setores, sendo a reforma construída, pari passu, sobre o arcabouço da Administração Burocrática. Na visão de Pereira (1996, p. 24), esta transição é importante, uma vez que inovações burocráticas tais como concurso público, sistema universal de remuneração, carreiras formalmente estruturadas, e sistema de treinamento devem ser conservados e aperfeiçoados, senão implantadas, pois a grande qualidade da administração pública burocrática é a sua segurança e efetividade, conjuntamente, de modo mais flexível, com os princípios da Administração Gerencial.

Por isso, no núcleo estratégico, onde estas características são importantes, ela deverá estar ainda presente, em conjunto com a administração pública gerencial. Já nos demais setores, onde o requisito de eficiência é fundamental dado o grande número de servidores e de cidadãos-clientes ou usuários envolvidos, o peso da administração pública burocrática deve ir diminuindo até praticamente desaparecer no setor das empresas estatais. (PEREIRA, 1996, p. 25).

A segunda etapa da reforma administrativa coincidiu com o segundo Governo de FHC (1999-2002) e exigiu reformas ministeriais, quando se deu a fusão do MARE com o Ministério do Planejamento, criando o atual Ministério do Planejamento, Orçamento e Gestão (MPOG), sob a orientação de outro Ministro, que teve a incumbência de continuar a reforma. Pereira (2001, p. 26) enfatiza que nem tudo ocorreu como previsto, pois as próprias Organizações Sociais não ganharam força e os concursos públicos anuais para carreiras de Estado foram descontinuados, a título de economia fiscal. Apesar disso, o Estado democrático e Gerencial continuava sua formação no Brasil.

Pode-se reconhecer que houve progresso da reforma em todas as áreas; nos Estados e Municípios, as ideias e princípios gerenciais continuam a ser implantados de forma consistente. Obviamente, tal implementação vai durar muitos anos no Brasil, perpassando governos até então defensores de uma gestão fiscal restritiva, mesmo que por meio de uma política de pessoal contrária ao receituário FHC porque, na concepção de Pereira (2001), constitui-se na transição de uma política de elites para uma democracia moderna.

\section{EFICIÊNCIA NOS PLANOS ADMINISTRATIVOS DO ESTADO BUROCRÁTICO E GERENCIAL}

Na elaboração de Drucker (1993), eficiência pressupõe "fazer certo um processo qualquer"; em sentido geral, a palavra eficiência tem sua raiz no termo latim efficientia, que se refere à capacidade de dispor de alguém ou de algo para conseguir um efeito determinado. Traduzindo-se, a eficiência trata do uso racional dos meios, dos quais dispõe para alcançar um 
objetivo previamente determinado. Junte-se a isso que tal conceito ${ }^{2}$, no contexto organizacional, agrega-se também aos conceitos de eficácia e efetividade.

Pela sua função e abrangência, a palavra eficiência pode ser usada em diferentes âmbitos. Nesse texto, abordamos o significado e o resultado da apropriação do termo nos planos administrativos da burocracia e do gerencialismo.

Foi por meio do detalhamento de um conjunto de regras, denominadas de características dentro de um sistema racional e instrumental, que Weber procurou organizar de forma estável (invariável) e duradoura (constante) a cooperação humana (equipe de trabalho), a fim de atingir objetivos formalizados para levar às organizações a máxima eficiência.

Para conseguir tal eficiência, o autor descreveu um tipo de estrutura burocrática ${ }^{3}$, entendendo que esta seria comum à maioria das organizações administrativas. No entanto, tal relação não é tão direta como está posta, pois Weber estudou a burocracia partindo da sociologia política e suas categorias, e não da teoria das organizações.

Contudo, o fato do autor ter observado o alcance da eficiência em algumas organizações, de antemão, só foi possível, porque tais características responderam; primeiramente, aquelas que se enquadraram naquele espaço-tempo. Na emergência de sistemas sociais mais adequados à industrialização, acabou por sobressaírem-se as "disfunções da burocracia" que, segundo Perrow (1993), são consequências de uma burocracia mal adequada. Katz e Kahn (1987) não perdoam a desconsideração da teoria com as variáveis ambientais e com a natureza das organizações. Chiavenatto (2003) critica seu sistema de controle ultrapassado e incapaz de resolver conflitos. Não custa alinhar outras críticas.

A adesão dos funcionários as regras e normas chegam ao ritual e consequentemente à ineficiência; a tomada de decisões que levem a eficiência fica prejudicada pela hierarquia, centralização e especialização visto que tendem a distorcer as informações. O modelo é muito mecanicista para ser eficiente em situações que exigem elevada capacidade de flexibilidade e de adaptação (MERTON, 1970, p. 271).

Isso comprova a incompatibilidade de sustentação da relação eficiência versus organizações de princípios rígidos, quando as organizações administrativas ${ }^{4}$ passam a ser entendidas pelo avesso, fortalecendo o contraponto dos estruturalistas, à luz do novo contexto,

\footnotetext{
2 Os conceitos de eficiência, eficácia e efetividade são distintos, porém interligados. Possuem significados completamente distintos, pois uma atividade pode ser desempenhada com eficácia, porém sem eficiência e viceversa e em relação ao conceito da efetividade, pode-se considerar como a prática da junção dos dois conceitos. Eficiência = 'fazer certo a 'coisa'; eficácia = 'fazer a 'coisa' certa; fazer certo na primeira vez, efetividade = 'fazer a 'coisa' que tem que ser feita'. http://www.tron.com.br - Acesso: 30/07/2013.

${ }^{3}$ Do modelo formalizado pelo autor, derivam-se três características: formalidade, impessoalidade e profissionalismo. Além disso, o autor defende a divisão entre planejamento e execução e enfatiza a separação entre politica e a administração pública.

${ }^{4} \mathrm{Em}$ se tratando de Brasil, a administração pública é regida por princípios que se encontram discriminada na Constituição Federal (art. 37), os quais são à base de toda a atividade administrativa e regulam as ações dos órgãos públicos e de seus administradores e servidores. Os princípios originais que constaram na CF/88 foram legalidade, impessoalidade, moralidade e publicidade. Porém, em 1998, as reformas administrativas que correram no mundo chegaram aqui por meio da Reforma administrativa do Estado, que exigiu alterações constitucionais, do que decorreu a Emenda Constitucional no 19/1998, a qual incluiu um novo princípio entre os já existentes - o principio da eficiência, visando garantir que a gestão pública seja cada vez menos burocrática para atingir seus objetivos, de forma mais rápida e eficaz. (Martins, 1985).
} 
o que vai resultar na reformulação ou ampliação das clássicas ideias de Weber. Inversamente, emerge o conceito de pós-burocracia.

A partir do início dos anos 70, os neoliberais propõem um modelo de Administração Pública, baseado na lógica do mercado e inspirado na filosofia liberal de Adam Smith, o que terá ressonância nas construções teóricas da Escola Public Choice. Para discutir os problemas da burocracia pública, esta partiu do individualismo metodológico, aliado ao instrumental econômico, utilizando-se de conceitos como utilidade, eficiência econômica e maximização. A conclusão é que, diferentemente da ideia de Weber, há uma associação simbiótica entre políticos e administração pública (burocratas).

A principal contribuição dessa proposta para o alcance da eficiência apontou para reformas nas estruturas modernas, objetivando diminuir a assimetria de informação, que dava vantagens aos burocratas. Por essa visão, maior eficiência é descrita em um modelo que combina menos burocracia com mais operações baseadas em mecanismos de mercado. Contudo, tais ideias defendidas por Niskanen, Buchanan, Ostrom, Tullock e outros teóricos daquela Escola terão seu apogeu com o fim do Welfare State (1980).

Foi ainda nos anos 80 que apareceu a Abordagem Gerencial ${ }^{5}$, cuja fase inicial era um modelo desestatizante que tinha a incumbência de introduzir a lógica da eficiência e da produtividade. Foi a vertente do gerencialismo puro $^{6}$ (britânico) que elegeu o princípio da eficiência para declarar guerra à velha engrenagem burocrática, o qual passou a atender as demandas dos contribuintes, por meio de estratégias da iniciativa privada.

Subsequentemente, surgiram dois modelos de administração pública pautadas no gerencialismo; a Administração Pública Gerencial (APG) e o Governo Empreendedor (GE), chamados de gerencialismo (managerialism). Ambos alinham-se aos valores de produtividade, orientação ao serviço, descentralização, eficiência na prestação de serviços.

A Administração Pública Gerencial ou Nova Gestão pública (New Public Management) é um modelo pré-burocrático para estruturar o gerenciamento da administração pública, baseado na eficiência e na competitividade. Pollitt e Bouckaert (2002) comparam esta a uma religião, devido a seu sistema de crenças baseadas na racionalidade instrumental. Na sequência, apresentamos um conjunto de prescrições operativas da APG, enunciadas por Hood (1995).

Desagregação do serviço público em unidades especializadas e centros de custos, competição entre organizações públicas e entre organizações públicas e privadas, uso de práticas de gestão provenientes da administração privada; atenção, disciplina e participação; administradores empreendedores com autonomia para decidir, avaliação de desempenho e avaliação centrada nos outputs. (HOOD, 1995, p. 95).

Em relação ao Governo Empreendedor (GE), Osborne e Gaebler (1992) a consideram "um estilo pragmático de gestão pública por meio da introdução das ferramentas da administração

\footnotetext{
${ }^{5} \mathrm{O}$ modelo passou por diversas etapas na Grã-Bretanha, desde o chamado gerencialismo puro até o Public Service Orientation (PSO), passando pelo Consumerism (qualidade e flexibilidade). Aspectos positivos foram introduzidos a cada fase, consolidando o denominado Managerialism ou Public Management.

${ }^{6}$ Esta corrente leva a sério a vertente economicista, com uma visão de eficiência fortemente ligada ao corte de gastos. Defende o comando da reforma administrativa nas mãos de um bem sucedido administrador privado, capaz de trazer ao setor público a experiência da gestão privada no trato das questões da eficiência, criando novo padrão organizacional de modernização. (Aragão 2005, p. 119).
} 
privada". Abaixo, em uma síntese, os autores exprimem os dez mandamentos sistematizados para o modelo GE.

Governo catalisador; governo que pertence à comunidade; governo competitivo; governo orientado por missão; governo de resultados; governo orientado ao cliente; governo empreendedor; governo preventivo; governo descentralizado e governo orientado para o mercado. (OSBORNE e GAEBLER, 1992, p. 79).

Na concepção Gerencial, os meios mais importantes para o alcance da eficiência, segundo Abrúcio (1997), podem ser sistematizados pelos seguintes itens: avaliação de desempenho; introdução de técnicas de controle orçamentário; descentralização administrativa; delegação de autoridade aos funcionários (empowerment) e administração por objetivos.

Como as anteriores, esse modelo administrativo também enfrentou profundas críticas, especialmente, no tocante à rígida estratégia de busca da eficiência.

Um ponto interessante diz respeito ao que se poderia chamar engessamento pela eficiência. Tal situação extrema seria alcançada quando, ao enfatizar ilimitadamente a dita estratégia, o gerencialismo puro caísse na armadilha da eficiência. Assim, critérios rígidos de definição, implementação e avaliação da eficiência impediriam o afloramento dos meios naturais para seu alcance, quais sejam, a flexibilidade e a capacidade inovativa. (ARAGÃO, 1997, p. 120).

Em se tratando de críticas, estas devem servir para que possamos entender as comparações e os conflitos que estão por trás de cada corpo teórico dominante em determinado contexto. No caso, será que priorizar os custos é o melhor e o mais adequado critério para considerar-se um serviço eficiente? Outro atenuante é a separação entre política e administração, ou seja, é uma técnica neutra e pura, que não é teórica e nem se sustenta, o que possibilitou que técnicas gerenciais do mundo privado adentrassem a administração pública, trazendo controvérsias como: a lógica do setor privado é totalmente desigual a do setor público e, obviamente, têm objetivos diferenciados. Tal relação é insustentável e tem ressonância na burocracia weberiana, da qual o gerencialismo se declarou inimiga.

Para Aragão (1997, p. 121), a principal crítica oferecida à estratégia da eficiência do puro gerencialismo inglês é a que o relaciona ao mecanicismo do fordismo-taylorismo. Pollitt (1993) vai mais adiante e reconhece nela o "neotaylorista", justamente pelo apego da constante busca da eficiência nos meios privados, para definir a concepção de uma administração pública eficiente.

O fato é que, apesar de toda a multiplicidade de conceitos teóricos e ideológicos que sustentam as reformas administrativas que, por vezes, confundem o cidadão/ consumidor/ cliente, por conta do descaso do conceito de público na administração pública, é importante a ressalva de que foram as características da vertente do gerencialismo puro que melhor conseguiram relacionar burocracia e eficiência na forma liberal de gestão pública. Tal influência inverteu, visivelmente, as funções profissionais no atual contexto das organizações, quando se exige que este seja multifuncional, polivalente e que permita tomar decisões autônomas para resolver as questões com eficiência. 


\title{
4 AVALIAÇÃO DA EDUCAÇÃO SUPERIOR NO GOVERNO FHC
}

O Estado brasileiro agora reformado passou a adotar o modelo Gerencial semelhante à iniciativa privada, o que o pressupõe mais ágil, eficiente e eficaz, centrado nos resultados, de acordo com Maués (2012), deixando a economia sob responsabilidade do mercado para assumir o papel regulador e avaliador das ações.

Segundo Dourado (2002, p.236), tal lógica implicou alterações substantivas no campo educacional, no que se refere à organização jurídica das IES, ao possibilitar, entre outros aspectos, novos processos de regulação, gestão e formatos de privatização na área educacional, em sintonia com os organismos multilaterais.

Portanto, acompanhando o conjunto de medidas adotadas pelo primeiro governo FHC (1995-1998) no âmbito da reforma do Estado brasileiro, implementada a partir da segunda metade da década de 90 , foi que tivemos as primeiras reformas na educação superior.

\begin{abstract}
O lugar da educação ficou bem definido nesse contexto do Estado reestruturado. À medida que a educação superior foi considerada como um serviço não exclusivo do Estado, podendo ser ofertada por Organizações Sociais, também denominadas de públicas não estatais, criou a necessidade de definição dos objetivos e a avaliação de resultados, observando os parâmetros de eficiência, eficácia e qualidade estabelecidos, em geral, pelas exigências do mercado (MAUÉS, 2012, p. 2).
\end{abstract}

Para o alinhamento com essa concepção, o Governo FHC, implementou uma série de instrumentos normativos (Leis, Decretos, Medidas Provisórias e Portarias), pelos quais o Estado assumiu papel destacado no controle e na gestão das políticas educacionais. Aprovou-se, inicialmente, a Lei 9192/95, que alterou a escolha dos dirigentes das IFES, determinou a composição do colégio eleitoral e permitiu a recondução de reitores e diretores aos cargos a serem ocupados por docentes adjuntos ou titulares. No entanto, foi a Lei 9131/95 que criou o Conselho Nacional de Educação (CNE), o qual instituiu "avaliações periódicas" nas instituições e nos Cursos superiores, pois referendou a Medida Provisória 1018/95, que criou o Exame Nacional de Cursos (ENC), apelidado de "Provão". Para ZAINKO (2008, p. 19), essa iniciativa caiu no gosto da população porque fez uma bem articulada campanha de marketing. Seguiu-se o Decreto no 2.026/96, que definiu os procedimentos para avaliação das IES e dos Cursos, com a criação da avaliação externa, por meio da Análise das condições de Oferta (ACO), posteriormente denominada de Análise das Condições de Ensino (ACE), porque baseada nas visitas in-loco de especialistas da área.

Isso demonstra que o governo procurou redefinir a essência da relação entre o Estado e o Sistema de Ensino Superior à luz do Plano Diretor da Reforma do Estado, quando aumentou a sua função credenciadora e reguladora do sistema. Na ideia de Souza (2005, p. 174), o aspecto mais importante dessa lei não foi o provão, mas a necessidade do recredenciamento periódico das IES, portanto, avaliação como controle e regulação.

Importante marco foi a aprovação da LDBEN 9394/96, seguida de outras normativas ${ }^{7}$ que ampliaram a burocratização, dando papel importante ao Estado no controle e na gestão das

\footnotetext{
7 Ver as seguintes normativas: Portaria no 249/1996; Portaria Ministerial no 880/1997; Portaria no 2040/1997; Portaria no 302/1998; Portaria no 635/1998; Portaria no 755/1999; Resolução no 02/1998; Decreto no 2.306/1997; Decreto no 2207/1997 e Decreto no. 3860/2001.
} 
políticas educacionais, de modo genérico, conferindo destaque para a flexibilidade/ fragmentação, por meio da diversificação institucional e da expansão pela via do setor privado, quando favoreceu as não lucrativas e também o setor empresarial.

Dados e fatos acumulados nesse período demonstram o acirramento da competição entre as próprias IES, o que lançou professores e coordenadores de cursos na defesa irrestrita de sua instituição, orientando e preparando (reforço) alunos para garantirem um conceito $A$, através de cursinhos paralelos aos próprios currículos formais.

$\mathrm{Na}$ realidade, isso reforçou uma estrutura burocrática nas IES, pois estas deveriam cadastrar aluno por aluno e os próprios alunos é que deveriam conferir se estavam inscritos pela instituição; caso contrário, deveriam acionar a Coordenação do Curso na justiça para garantirem o seu direito. Porém, tais ações acarretaram ônus em todos os sentidos aos concluintes. Foi assim que os exames orientados para a obtenção de resultados permitiram maior controle sobre as IES, reduziram a autonomia profissional e fizeram aumentar o poder burocrático e coercitivo do Estado.

Esse poder "legiferante" do legislativo de multiplicar normativas, em tão pouco tempo, encaixa-se nas exigências do Banco Mundial para a reforma na educação superior, pois trata da redução dos gastos e da defesa da diversificação das fontes de financiamento, como se evidencia no Relatório La Enseñansa.

(...) maior autonomia institucional é a chave para a reforma do ensino público, especialmente a fim de diversificar e utilizar os recursos mais eficientes (...), por isso os governos deverão efetuar reformas importantes no financiamento a fim de mobilizar mais recursos privados para o ensino superior em instituições estatais (...) de várias maneiras: a participação dos estudantes nos gastos, arrecadação de recursos de ex-alunos, utilização de fontes externas, realização de outras atividades que gerem receitas (BANCO MUNDIAL, 1995, p. 44).

Esse panorama nos oferece ricos detalhes para que possamos investigar a política de avaliação no Brasil, por meio da burocracia estatal e de suas ligações com as políticas clientelísticas, através dos grupos de interesse. Como vimos anteriormente, a questão da burocracia ainda é central na discussão dos problemas relacionados ao papel do Estado e suas relações com a educação superior. Isso torna importante a compreensão das "funcionalidades e disfuncionalidades", portanto, aquilo que não é eficiente pode ser explicado pela ausência de inovação, de flexibilidade, de criatividade, de controle, dos aparelhos burocráticos.

Fica evidente que, alinhado a isso, estava a transição da burocracia para o modelo de Estado Gerencial, pois para defender o afastamento do Estado da manutenção plena da educação superior pública, os vetos do Presidente FHC à Lei no 10.172/2001, que tratou do Plano Nacional de Educação (PNE-2001), incentivaram a livre competição de mercado entre as IES. Com isso, a nova administração afastou-se apenas dos gastos, mantendo a gestão total do sistema, através da utilização de mecanismos de controle das IES, da imposição de instrumentos normativos que (re)definiram a organização geral do sistema e da avaliação, com escolha de dirigentes, credenciamento e recredenciamento de IES, exames para alunos. Na teoria weberiana, isso legitima uma sociedade e uma autoridade burocrático-legal, do que se pode inquirir que a emergência da avaliação significou ampliação do controle burocrático.

Portanto, foi sob o signo do ordenamento jurídico e legal que se instaurou a capacidade de alterar as relações entre universidade e poder público, como parte de uma política de 
modernização "eficiente" do ensino superior. O ponto central disso será a concessão pelo Estado de "autonomia plena" para as instituições e de "flexibilidade", necessária para o enfrentamento da crise que vivenciam. $\mathrm{O}$ argumento é de que o Estado substituiria os controles burocráticos e detalhistas por um sistema que combinasse a autonomia de execução e a avaliação de desempenho, alterando o sistema de alocação de recursos, de forma a subordiná-lo à avaliação do desempenho das IES.

Ao analisar a política de avaliação oficial, Dias Sobrinho $(1999$, p. 68) afirma que um dos grandes problemas desse tipo de avaliação é que requer informações simples e rápidas, atendose, quase exclusivamente, aos produtos ou resultados.

Decorrido mais de uma década, o resultado desse modelo de avaliação compulsórioperiódica de supervisão, regulação, e controle, pela ótica do Estado Gerencial, mas também Burocrático, mostrou-se mais eficiente para produzir novos tipos de educação superior, mais flexíveis e adequados ao desenvolvimento econômico, em contraposição à agonia do ensino superior público, que deixou de ser uma prioridade para o Estado.

Conclui-se que foi a prioridade dada ao pilar da regulação que redefiniu a relação entre Estado e educação superior pelas coordenadas do Estado burocrático e gerencial. Isso tornou possível preparar e sedimentar o terreno para o redesenho da educação superior imposto pela Europa do conhecimento à América Latina, sob a inspiração da reforma proposta pela Declaração de Bolonha (1988), haja vista o aperfeiçoamento de tal modelo, por meio de mudanças de caráter eficiente ${ }^{8}$, tão somente técnico, introduzidas na prática, a partir de 2003, no Governo Lula da Silva.

\section{A TENSÃO ENTRE EFICIÊNCIA, BUROCRACIA E AVALIAÇÃO.}

As considerações expostas no corpo desse trabalho nos encaminham para as seguintes considerações.

O cenário da reforma do Estado brasileiro, que teve início no primeiro Governo FHC, foi implementada por meio da adoção de uma série de ajustes estruturais da economia, refletiu diretamente sobre a política educacional, trazendo profundas mudanças para a educação superior.

O Estado brasileiro, que passou a adotar o modelo da Administração Gerencial, próprio da área privada, assumiu papel de regulador e avaliador em todas as esferas sociais, já que ficou para o poder público a responsabilidade da definição dos objetivos e a avaliação de resultados, com base nos parâmetros de eficiência, eficácia e qualidade, exigidos pelo mercado. Portanto, foi na transição do modelo de Estado gerencial que se inscreveu a incorporação formal e definitiva da avaliação do ensino superior como ato regulatório e compulsório no país.

\footnotetext{
${ }^{8}$ No primeiro Governo Lula da Silva, foi aprovada a Lei $10.861 / 2004$, que criou o Sistema Nacional de Avaliação da Educação Superior (SINAES), a qual expande as dimensões da avaliação, integrando novas ferramentas e postulando uma avaliação externa e interna. Constituída por três tipos de avaliação: Institucional, dos cursos e dos estudantes, ao integrá-las, trouxe de volta a visão da avaliação formativa, mas, em 2008, continuado a predominância do setor privado, volta a ter importância os resultados dos exames na composição de índices e indicadores para a regulação do sistema, perdendo o caráter formativo de avaliação para qualidade social.
} 
Entretanto, contraditoriamente, tal implementação só foi possível por meio de práticas quase que exclusivamente burocráticas, ancoradas no excesso de legislações, o que colocou as IES diante de uma complexidade crescente de exigências a serem cumpridas em determinado prazo. Foi possível perceber que, naquele contexto, não era viável uma política pública não burocrática, devido à importância que tais características assumiram.

O certo é que não ocorreu uma desburocratização no processo de avaliação, mas uma adaptação do uso da burocracia ao novo contexto organizacional, rígida (hard), em alguns aspectos, e flexível (light), em outros. Portanto, foi uma condição situacional que atendeu, de modo eficiente, ao objetivo maior do Estado. Foi assim que, na corrida contra o tempo, as IES trataram de se alinhar ao pano de fundo expresso em normas, regulamentos e rotinas.

Tal alinhamento, necessariamente, não quer dizer concordância, mas pode ser traduzido pela concepção de que organização flexível é aquela que dispõe de rapidez e de facilidade para deslocar recursos de uma atividade para outra, pois em uma era de competição global, a sobrevivência depende da capacidade de adaptações rápidas.

Enquanto política pública, a avaliação implementada no Governo FHC, por meio da ENC e da ACE, tão somente tratou de cumpriu papel determinante de regular e controlar a educação superior, portanto, não se identificou ou se aproximou de um processo de caráter mais global como possibilidade de um processo democrático e emancipatório, capaz de questionar rigorosamente toda a instituição.

Para atingir seu objetivo, todo o processo foi atravessado por recursos burocráticos que deram um efeito especial ao favorecer que o Estado implantasse, de modo eficiente, políticas de descentralização, de diversificação, de expansão e, consequentemente, de privatização, em contraposição às melhorias na educação superior.

Pelo seu percurso técnico e instrumental, quando se analisa as bases teóricas e os passos mecânicos de como se deu tal processo, observa-se que o objetivo foi tão somente para cumprir exigências, cujos resultados podem ser traduzidos por levantamentos de dados quantitativos que, jogados na mídia, transformam-se em rankings que fomentam a competição e a comparação entre as IES e os cursos.

Uma coisa é certa, tal política gerou uma tensão entre burocracia, eficiência e a própria avaliação quando, por um lado, os alunos eram forçados a participar do Provão através de exigência, intimidação e retenção do diploma, o que se configurava em uma punição; por outro, as IES eram pressionadas a atender todas as exigências do MEC, ou seja, cumprir prazos renderse ao guião prescritivo, por vezes, mascarando as informações e até a realidade desvelada por processos locais transparentes de autoavaliação.

Conclui-se que a política pública de avaliação da educação superior nos dois governos FHC manteve e ampliou a burocracia, surtindo efeito de uma prática padronizada, que instigou um processo mais linear, mais rígido, menos qualitativo, por isso, incapaz de enfrentar a complexidade do que é avaliar em nosso tempo.

\section{REFERÊNCIAS BIBLIOGRÁFICAS}

1. ABRÚCIO, Fernando Luiz. O impacto do modelo gerencial na administração pública: um breve estudo sobre a experiência internacional recente. Cadernos ENAP. Brasília, ENAP, no 10, 1997. 
2. ARAGÃO, Cecília V. Burocracia, eficiência e modelos de gestão: um ensaio. Revista do Serviço Público. Ano. 48 no 3, set-dez 1997.

3. AVELAR, Lúcia. Clientelismo de Estado e política da educação brasileira. Educação \& Sociedade, Campinas, v. 17, n. 54, p. 34-51, abr. 1996.

4. BANCO MUNDIAL. La enseñanza superior: las lecciones derivadas de la experiencia. Washington, 1994. Disponível em: <http://www.bancomundial.org.br>. Acesso: 14 set. 2012.

5. BRESSER-PEREIRA, Luiz Carlos. Reflexões sobre a reforma gerencial brasileira de 1995. Disponível em: www.bresserpereira.org.br/papers/1995. Acesso: 09 junho 2013.

6. __ _ _ Do Estado patrimonial ao gerencial. In: Pinheiro, W. e Sachs (Orgs.). Brasil: um século de transformações. São Paulo. Cia das Letras. 2001.

7. BRASIL. MARE. Plano Diretor da Reforma Administrativa do Estado. Brasília. 1995.

8. CARDOSO, Fernando Henrique; FALETTO, Enzo. Dependência e desenvolvimento na América Latina: ensaio de interpretação sociológica. 7. Ed. Rio de Janeiro: LTC, 1970.

9. CHIAVENATTO, Idalberto. Administração nos Novos Tempos 2a edição. Ed. Campus 2003.

10. DIAS SOBRINHO, José. Avaliação institucional: marcos teóricos e políticos. Avaliação. Campinas, v. 1, n. 1, p. 9-14, jul. 1999.

11. DOURADO, L. F. Reforma do Estado e as políticas para a educação superior no Brasil nos anos 90. Educação e Sociedade. Campinas. Vol. 23, n. 80, setembro 2002.

12. DRUCKER, Peter. The effective executive. Harper Collins Publishers, 1993

13. DRAIBE, Sônia. Rumos e metamorfoses: um estudo sobre a constituição do Estado e as alternativas da industrialização no Brasil: 1930-1960. Rio de Janeiro: Paz e Terra, 1985. (Estudos brasileiros, 84).

14. FAORO, Raimundo. Os donos do poder: formação do patronato político brasileiro. 9. Ed. São Paulo: Globo, 2 v. 1958.

15. GIRGLIOLI, Pier Paolo. Burocracia. In. Bobio Norberto. Et alii. Dicionário de Política. 7. Ed. Brasília, UnB V. 1, 1995.

16. GOUVÊA, Gilda Portugal. Burocracia e elites burocráticas no Brasil. São Paulo: Paulicéia. 1999.

17. HOOD, C. The New Public Management in the 1980's: variations on a theme. Accounting. Organizations and Society, 1995.

18. KATZ, Daniel \& KAHN, Robert. Psicologia social das organizações. Trad. Auriphebo Simões. 3 ed. São Paulo, Atlas, 1987.

19. LANE, Jan E. The public sector: concepts, models and approaches. Sage. 1993.

20. MAFRA, Francisco. Administração pública burocrática e gerencial. (2010). Disponível em: www.ambitojuridico.com.br. Acesso: 09 de junho de 2013.

21. MARTINS, Luciano. Estado capitalista e burocracia no Brasil pós-64. 2. Ed. Rio de Janeiro: Paz e Terra, 1985. 
22. MAUÉS, Olgaíses. A política de avaliação da educação superior e os desafios da implantação do SINAES. Disponível em: http://www.anped.org.br/reunioes/30ra/trabalhos/GT112988--Int.pdf. Acesso: 12 de julho de 2013.

23. MERTON, Robert C. Teoria da Rational. Opções de preço. Jornal de Economia e Gestão da Ciência. 1970.

24. OSBORNE, David e GAEBLER, Ted. Reinventando o governo. Brasília: Editora MH Comunicação, 8a ed., 1992.

25. PERROW, Charles. Ataque Radical em Negócios. (Harcourt Brace Jovanovich). 1972.

26. POLLITT, Christopher. Managerialism and the public services: cuts or cultural change in the 1990s? 2. Ed. Oxford, Blackwell, 1993.

27. POLLITT, Christopher; BOUCKAERT, Geert. Avaliando reformas da gestão pública: uma perspectiva internacional. Revista do Serviço Público, v. 53, n. 3, p. 5-30, 2002.

28. PIRES, J. C. L.; PICCININI, M. S. A regulação dos setores de infraestrutura no Brasil. In: GIAMBIAGI, F.; MOREIRA, M. M. (Org). A economia brasileira nos anos 90 . Rio de Janeiro: BNDES, 1999. Disponível em: http://www.bndes.gov.br/SiteBNDES/export/sites/...pt/.../eco90 a.pdf>. Acesso: 3 out. 2012.

29. SOUZA, Paulo Renato. A revolução gerenciada: educação no Brasil, 1995-2002. São Paulo: Prentice Hall, 2005.

30. ZAIKO, Maria Amélia S. Políticas públicas de avaliação da educação superior: conceitos e desafios. Jornal de políticas educacionais. № 4 julho-dezembro 2008.

31. WEBER, Max. Ensaios de sociologia. 5. Ed. Rio de Janeiro: LTC, 1983.

32. BRASIL. Constituição. Constituição da República Federativa do Brasil; promulgada em 05 de outubro de 1988: atualizada até a Emenda Constitucional n. 20, de 15 de dezembro de 1998. São Paulo. Saraiva. 2003.

33.BRASIL. Lei n. 9.192/95, de 24 de novembro de 1995. Altera os dispositivos da Lei 4024/61 e dá outras providências. In: BASTOS, A. W. Coletânea da legislação educacional brasileira. Rio de Janeiro: Lúmen Júris, 2000.

34. Lei n. 9.131/95, de 24 de novembro de 1995. Altera os dispositivos da Lei 4024/61 e dá outras providências. In: BASTOS, A. W. Coletânea da legislação educacional brasileira. Rio de Janeiro: Lúmen Júris, 2000. P. 46-52.

35. Lei n. 9.394/96, de 20 de dezembro de 1996. Estabelece as diretrizes e as bases da educação nacional. In: SENADO FEDERAL. Secretaria Informação e Documentação. Subsecretaria de informações. Legislação Republicana Brasileira. Brasília, DF, 2002. 1 CD-ROM.

36. Lei n. 10.172, de nove de janeiro de 2001. Aprova o Plano Nacional de Educação e dá outras providências. Diário Oficial [da] República Federativa do Brasil, Brasília, DF, 10 jan. 2001. Seção I.

37.BRASIL. Medida Provisória n. 1.018, de 8 de junho de 1995. Altera dispositivos da Lei no 4.024/61 e dá outras providências. Disponível em: http://www.senado.governo.br/legbras/>. Acesso: 9 out. 2012. 
38.BRASIL. Decreto-Lei n.200/1967. Legislação Republicana Brasileira. Brasília, DF, 1990. 1 CDROM.

39. Decreto n. 2.026, de 10 de outubro de 1996. Estabelece procedimentos para o processo de avaliação dos Cursos e Instituições de Ensino superior. Diário Oficial [da] República Federativa do Brasil, Brasília, DF, 11 out. 1996. Seção I, p. 4.686. 